\title{
The PID Parameter Setting for the Hydraulic Servo System Based on Genetic Algorithms
}

\author{
Yao Yao ${ }^{1, a}$, Wang Pengfei ${ }^{1, b}$, Zhang Wenyu ${ }^{1, c}$, Wu Hualiang ${ }^{2, d}$ \\ ${ }^{1}$ University of Science and Technology Liaoning, Anshan Liaoning 114051 \\ ${ }^{2}$ Abrasion of Angang Steel Co., LTD., AnshanLiaoning 114021 \\ akdyy1216@163.com, b605822348@qq.com, czhangwenyu@126.com, ${ }^{\mathrm{d}} 49911944 @ q q . c o m$
}

Keywords: The hydraulic servo system, PID controner, genetic algorithms

Abstract: This paper is based on the magnesium alloy in our school laboratory rolling machine as the research object and the servo system model of valve controlling hydraulic cylinder is established, by using genetic algorithms to optimize PID controller design and to control its model. The simulation and experiment results show that the genetic algorithms applied to PID controller optimization design is feasible and effective.

\section{Introduction}

PID controller is one of the earliest developed control strategies. Because design algorithm and control structure involved in PID controller are simple, and are suitable for engineering application background. Moreover, PID control scheme does not require accurate mathematical model of controlled object, and the control effect of PID control is commonly satisfactory. So PID controller in industry is one of the most widely used control strategies, and is more successful. According to statistics, PID controller occupies more than $90 \%$ in the industrial control of the controller. PID controller with proportional coefficient and integral coefficient, differential coefficient of three parameters need to design and tune, the sampling period of system parameters need to choose. Therefore, it is very difficulty to design the ideal parameters. Traditional methods are commonly used algorithms, such as Ziegler-Nichols tuning formula, Chien-Hrones-Reswick tuning algorithm, the optimal parameters for empirical formula and the genetic algorithm[1]. These all belong to experience design methods, different target functions corresponding to different experiences, and finishing knowledge base is a long time engineering. So we choose the genetic algorithm for parameter optimization. This method doesn't need any initial information to seek the global optimal solution, which is a highly efficient optimization combination method.

\section{Question}

This paper studies casting machine hydraulic servo control system [2] - [6], the control block diagram is shown in figure 1.

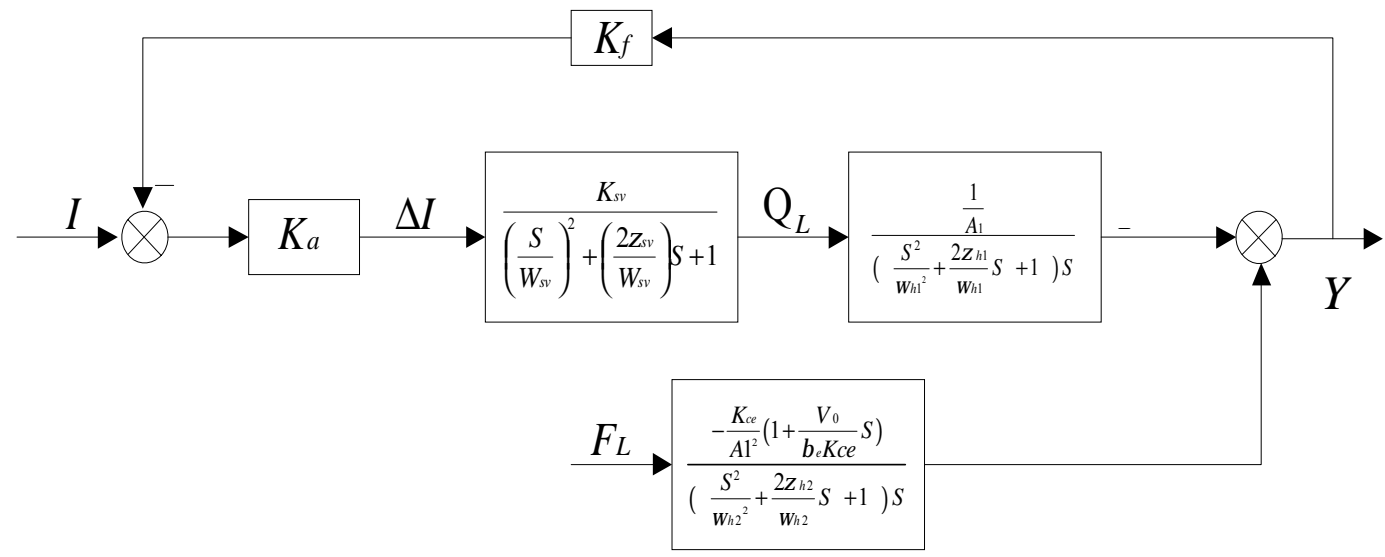

Fig.1 Hydraulic servo control block diagram of rolling machine roll gap control

The above parameter values are shown in table 1. 
Table 1 Valve controlled hydraulic servo system parameter table

\begin{tabular}{cccc}
\hline Sign & Value (Unit) & Sign & Value (Unit) \\
\hline$K_{a}$ & 1 & $A_{1}$ & $5.03 \times 10^{-3} \mathrm{~m}^{2}$ \\
$K_{s v}$ & $0.0625\left(\mathrm{~m}^{3} / \mathrm{s}\right) / \mathrm{A}$ & $\omega_{h 1}$ & $392.75 \mathrm{rad} / \mathrm{s}$ \\
$W_{s v}$ & $502.4 \mathrm{rad} / \mathrm{s}$ & $\zeta_{h 1}$ & 0.2 \\
$\zeta_{s v}$ & 0.7 & $K_{f}$ & 2.13
\end{tabular}

Assume that the input is 1, we can get the system step response curve, as shown in figure 2. According to the step response curve, the system reaches steady at about $4 \mathrm{~S}$ at about $4 \mathrm{~s}$, but its adjustment time is longer. So it did not meet the requirements of the time response of cast rolling experiments.

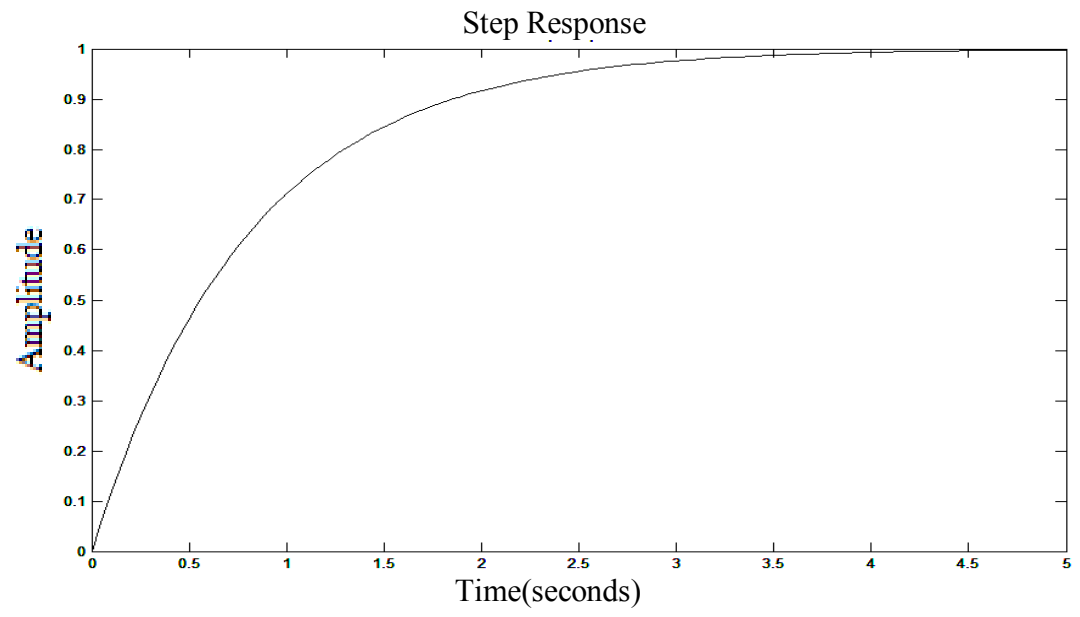

Fig.2 Step response curve

\section{Optimal control problem solving based on the genetic algorithm}

If you want to design the optimal controller for it, simulation block diagram can be set up by using Simulink tool -box as shown in figure 3 [9].

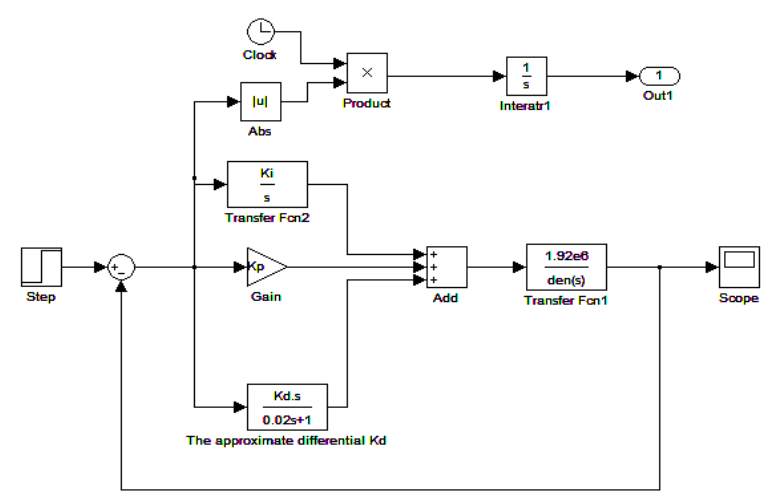

Fig.3 Optimal control simulation block diagram

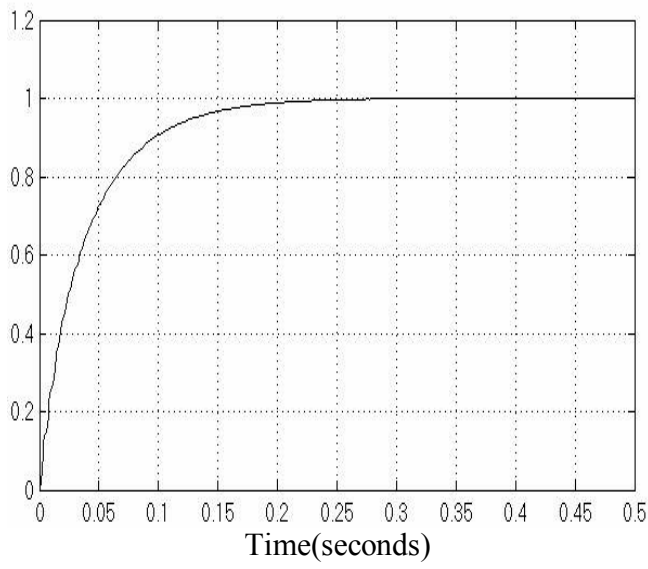

Fig.4 System simulation results

In practice, pure differential link cannot be used directly and usually we can use a first-order link with filtering function to describe it, at this time:

$$
G_{c}(s)=K_{p}+\frac{K_{i}}{s}+\frac{K_{d} s}{T_{f} s+1}
$$

Among them, $\mathrm{T}_{f}$ is filtering time constant, this paper take 0.02.Suppose searching the optimal solution of the problem in the range of $(0.1,20)$, you can enter the following command in the MATLAB workspace.Corresponding value $\mathrm{K}_{\mathrm{i}}=0.2167, \mathrm{~K}_{\mathrm{p}}=20, \mathrm{~K}_{\mathrm{d}}=0.100$, Under the action of the 
controller, step response is shown in figure 4 . The adjustment time of the system is $0.28 \mathrm{~s}$, thus ensure hydraulic servo control system has better stability, quickness and accuracy. Every time due to the randomness of the genetic algorithm itself, the results may vary widely in this case. But the optimal value of the objective function is similar, the control effect is similar.

\section{Experimental results}

In order to detect the responsiveness of the system after the PID adjustment, we have made the following three experiments. The casting machine roll gap of the lab is $2.35 \mathrm{~mm}$ in the closed state and PLC program processing time is $0.2 \sim 0.3 \mathrm{~ms}$. This time is too small, which does not affect the convergence effect. Signal sampling time for PLC AI is $45 \mathrm{~ms}$.

Experiment 1: roll material: aluminium alloy $\left(680 \sim 690^{\circ} \mathrm{C}\right)$; casting roller speed $12 \mathrm{~m} / \mathrm{min}$; Figure 5 shows the convergence of roll gap in Experiment 1. The abscissa of the figure is time (100 $\mathrm{ms}$ ), the vertical is roll gap ( $\mathrm{mm})$.From figure can be analyzed that the control effect is good, the convergence time of the roll gap is $1.4 \mathrm{~s}$ and overshoot is close to $13 \%$. After $1.4 \mathrm{~s}$ roll gap roughly maintain in $5.5 \mathrm{~mm}$ and is basically stable.

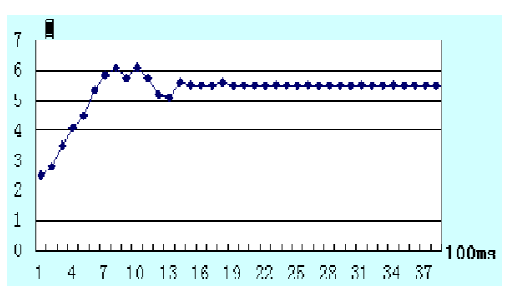

Fig.5 Roll gap in Experiment 1

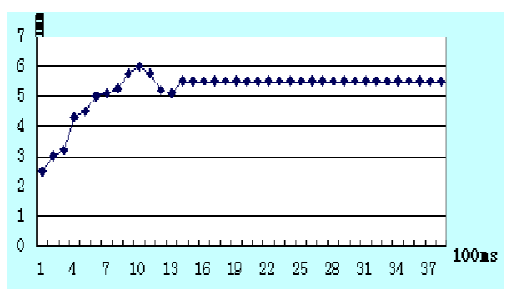

Fig.6 Roll gap in Experiment 2

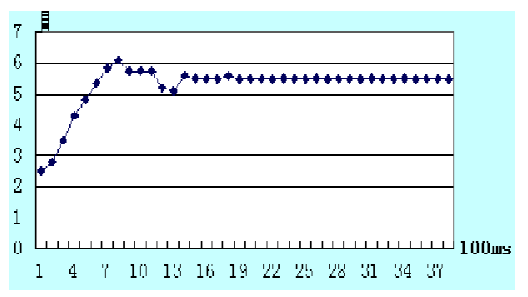

Fig.7 Roll gap in Experiment 3

Experiment 2: roll material: aluminium alloy $\left(680 \sim 690^{\circ} \mathrm{C}\right)$; casting roller speed $8 \mathrm{~m} / \mathrm{min}$; Figure 6 shows the convergence of roll gap in Experiment 2.The abscissa of the figure is time (100 $\mathrm{ms})$, the vertical is roll gap $(\mathrm{mm})$.From figure can be analyzed that the control effect is good, the convergence time of the roll gap is $1.4 \mathrm{~s}$ and overshoot is close to $12 \%$. After $1.4 \mathrm{~s}$ roll gap roughly maintain in $5.5 \mathrm{~mm}$ and is basically stable.

Experiment 3: roll material: magnesium alloy $\left(680 \sim 690^{\circ} \mathrm{C}\right)$;casting roller speed $12 \mathrm{~m} / \mathrm{min}$; Figure 7 shows the convergence of roll gap in Experiment 3.The abscissa of the figure is time (100 $\mathrm{ms})$, the vertical is roll gap $(\mathrm{mm})$.From figure can be analyzed that the control effect is good, the convergence time of the roll gap is $1.4 \mathrm{~s}$ and overshoot is close to $14 \%$. After $1.4 \mathrm{~s}$ roll gap roughly maintain in $5.5 \mathrm{~mm}$ and is basically stable.

After by comparing the convergence figure for Experiment 1 and 2 of the roll gap, we can come to a conclusion that roll material is constant, by changing the casting roll speed almost no influence on the maximum overshoot, convergence time and the size of the roll gap through PID control system. After by comparing the convergence figure for Experiment 1 and 3 of the roll gap, we can come to a conclusion that roll speed is constant, by changing the roll material almost no influence on the maximum overshoot, convergence time and the size of the roll gap through PID control system. Based on the above analysis, drawing a conclusion that it can run steadily through the PID control system under different working conditions and meets the requirements of overshoot and stability. The thickness of the plate casted out is basically in the range of allowable deviation . This system is suitable for using PID regulation as a major means of control. 


\section{Conclusion}

Using genetic algorithm for PID controller parameters optimization, combining with an instance of casting machine hydraulic servo system simulation, genetic algorithm has obvious advantages in parameter optimization speed and effectiveness is verified. With optimization simple and efficiency high, genetic algorithm is an ideal method for PID controller parameters optimization.

\section{Acknowledgements}

The research work is supported by project of Anshan technology in Liaoning province of China: research and development platform of magnesium alloy rolling machine and hydraulic servo AGC system development and application of magnesium alloy rolling machine, and contributions of University of Science and Technology Liaoning and Abrasion of Angang Steel Co., LTD. to this paper are gratefully acknowledged.

\section{References}

[1] Liu Jinkun: Advanced PID control and MATLAB simulation (Tsinghua university press, Beijing 2011).

[2]Song Zhian:Hydraulic Servo Control System Analysis and Design based on MATLAB(National Defence Industry Press, Beijing 2007).

[3]You Zhangping and Wang Weifeng:Dynamic simulation of hydraulic servo system based on SIMULINK,Machine Tool \& Hydraulics, 2004(6),p.47-49.

[4]Wang Xingyu and Su Jian:Hydraulic system modeling and simulation of railway vehicle bogie test bed, Chinese Hydraulics and Pneumatics ,2009(6),p.8-11.

[5]Hang Jiang and Xiao Yang:hydraulic servo system modeling and simulation of the new servo hydropress pump control hydraulic cylinder,Chinese Hydraulics and Pneumatics, 2011(10) ,p.12-15.

[6] Ying Xin, Yao Yao, Ming Liu and Wenyu Zhang :Establishment of Valve Control Mathematical Model of Hydraulic Differential Cylinder,Advanced Materials Research ,Vols.542543(2012),p.1124-1131.

[7]Ren Shan and Li Wei:Simulation Analysis for Servo System in Cylinder Controlled by Servovalve Based on MATLAB,Equipment Manufacturing Technology, 2009 (9) ,p.32-33.

[8]Wang Yushan and Zhai Hua:Precise straightening machine simulation analysis for hydraulic servo system, Machine Tool \& Hydraulics, 2010(10) ,p.23-25.

[9]Xue Dingyu:Control System and Application of Computer Auxiliary Design - MATLAB language and application (3rd edition), Tsinghua university press, Beijing(2012). 